\title{
Study of Piano Teaching during Preschool Education Based on Aesthetic Education
}

\author{
Qinna Xu \\ College of Primary Education \\ Linyi University \\ Linyi, China
}

\begin{abstract}
The cultivation of students in aesthetic ability is one of the important teaching objectives of piano teaching in preschool education. We should understand the nature of piano class in pre-school education, explore the influence factors of piano education on the cultivation of students' aesthetic quality, and find the path for piano teaching of aesthetic education based on the preschool education, which has significance for enhancing the aesthetic ability of students in pre-school education.
\end{abstract}

Keywords-aesthetic education; pre-school education; piano teaching; aesthetic ability

\section{INTRODUCTION}

In preschool education, we should cultivate kindergarten teachers for the future, during which aesthetic education is an important issue, closely related to the development of students' ability and having far influence on their future work in early childhood education. In recent years, with the reform of basic piano teaching in pre-school education, the study field has become more and more open and gradually reflected the specialties of "teacher training". The research on aesthetic education is based on piano art and human life meaning to highlight the fundamental value and significance of basic piano teaching in pre-school education. If we set aesthetic education in the piano teaching process, students' interest in learning piano will be stimulated greatly, their aesthetic ability will be improved, and their good humanistic quality will form easily.

\section{ThE NATURE OF PIANO ClASS OF PRE-SCHOOL EDUCATION}

Piano course is compulsory for pre-school education, which is to improve the students' aesthetic consciousness and ability by teaching piano playing, so that they can be qualified to act as the main course teacher in their future kindergarten teaching. Compared with other courses of pre-school education, piano class has its unique nature in students' aesthetic education.

\section{A. Emotion}

Emotion is the most important characteristic of piano teaching. Piano teaching is not only an accurate presentation of skills, but more importantly an emotional communication through the audio expression. "The purpose of musical performance is not to cause the tonal and acoustic sound wave movement, but to arose the deep psychological experience by adding the internal emotional dynamic form (emotion) in the transition from musical notation to auditory sound, so as to endow with the vitality of life in the abiotic form and bring a humanistic experience." Piano teaching can create a good way for students to add emotion into the music, and make students further gain a sense of musical form by playing piano, improve their aesthetic emotion, thus actively experience composer's emotions in the works, and fully express their feelings for music.

\section{B. Humanity}

Music is a human art, is a valuable spiritual wealth of mankind. Music is derived from the history of human development, and different cultures give birth to different music. From its emergence, piano art has gone through over 300 years of development; the change of piano and the abundance of works as well as the performance and creation of performers and composers to a certain extent all reflect people's cultural ideology under the background of a certain era. Moreover, the piano with its rich expression has not been only of the West, but of the world; it is well added with many national culture and a variety of folk music matter, showing a unique style. The study of aesthetic culture is an important part of aesthetic study of music, and without full understanding of culture, it is impossible to truly understand the inherent charm of music. Therefore, we should pay great attention to its rich humanities in the piano teaching of pre-school education.

\section{Integration}

Piano playing is a process of creating beauty, during which students can express their experience of life, understanding and emotion for the works through music, so that students can integrate their aesthetic experience and their music theory into the play, and achieve the multi-directional interaction of music performance, feelings and theoretical understanding. In a number of music theory courses, many students make a study in a symbolic and completely rational way, such as harmony, music form history and so on, and piano provides a change to integrate these theories into the real sound and to make students participate in the understanding of the form and content of music in a emotional way, so that the aesthetic ability of students is improved wholly. 


\section{Artistic Skill}

Piano playing is a highly artistic aesthetic activity, and in the piano teaching, the teaching of "skill" is necessary, which is the means and method of aesthetic expression and also the necessary way to transmit aesthetic information. The learning of piano skills has certain independence, and generally only repeated exercise for bones and muscles can learn and maintain the correct action, while the independence is relative, and hands should do action based on the sound requirements, otherwise any performance inconsistent with sound is meaningless. Therefore, generally "artistic skill" is included in the "aesthetic". The piano course of pre-school education can make students acquire a certain aesthetic performance method through the study of skills, so as to promote their comprehensive aesthetic ability.

\section{THE FACTORS OF INFLUENCE OF PIANO TEACHING OF} PRE-SCHOOL EDUCATION ON THE CULTIVATION OF AESTHETIC QUALITY OF STUDENTS

As a course, piano class is not a single element but a system, and it has a whole framework, consisting of the nature of the curriculum, training objectives, setting of curriculum, teaching form, teaching content and other elements. The piano course of preschool education is an approach to achieve the cultivation of aesthetic quality of music, which means that the cultivation of aesthetic quality of music will be influenced by each element of piano course system.

\section{A. The Influence of Training Objectives on the Aesthetic Quality of Music}

The objective of training is the primary problem to be solved in the research of curriculum, and generally, it is "what is the course learned to cultivate, what is the purpose to study the course." The objective of training has the guiding function for teaching, based on which the curriculum is set, the teaching form and the teaching content are determined, and it directs the development of music teaching. Therefore, for the cultivation of aesthetic quality in the piano teaching of preschool education, we must first include it into the training objectives, and take the cultivation of aesthetic quality as one of the training objectives of piano teaching of pre-school education. In this way, teaching activities will be carried out according to the aesthetic quality standard. In other words, as the training objective of piano teaching in pre-school education, the aesthetic quality of music is the prerequisite and basis to carry out the piano class of pre-school education.

\section{B. The Influence of Curriculum Setting on the Cultivation of Aesthetic Quality of Music}

Curriculum setting refers to the establishment and arrangement of various courses selected by a certain school. The basic contents include: 1) the setting of teaching subjects, subject types; 2) the order of subjects; 3 ) the allocation of class hours: 4) the basic principles of perennial preparation.

Piano class is a very practical course, and it needs the support of many courses in theory. It is inextricably linked with many courses such as harmony, music form, polyphony, music aesthetics, and piano art history. The courses are interrelated and interdependent, and their curriculum frameworks determine the cultivation of the students of preschool education. To achieve the goal of training aesthetic quality in the piano class, we must meet the requirements of training aesthetic quality in terms of the allocation of class hours, the type of subject, and the connection with related disciplines, etc., and make reasonable curriculum setting to create conditions for carrying out aesthetic quality training in piano class. The setting of curriculum is to provide necessary and sufficient objective conditions for the aesthetic quality training in piano class. Only when the curriculum setting of piano class meets the requirements of the cultivation of aesthetic quality of music, it is possible to realize the goal of cultivating the aesthetic quality of music in piano class.

\section{The Influence of Teaching Form on the Aesthetic Quality Training}

Teaching form is an operable method to enable students to comprehend their knowledge by learning, enhance their selfawareness and cultivate their correct values. With the technological progress and equipment update, modern teaching form is becoming more diverse, and each form of teaching has its characteristics, respectively with their own advantages and disadvantages. We should analyze the advantages and disadvantages of each form of teaching, and select the appropriate methods for teaching according to different training objectives. In the class teaching, if the teaching form is proper and the advantages of teaching form are brought into full play, the teaching atmosphere, class organization, students' learning interest and subjective initiative all will develop towards the teaching objectives, getting great effect. Contrarily, it will get less effective. Therefore, in the piano class, the appropriate form of teaching is helpful and accelerative for the cultivation of aesthetic quality of music, but the inappropriate teaching form is impeditive for the cultivation of aesthetic quality of music.

\section{The Influence of Teaching Content on the Cultivation of Aesthetic Quality of Music}

Teaching content refers to the knowledge, skills, technique, ideas, viewpoints, beliefs, language, behavior, habits and summary taught by the school to students, and generally it is "what will be taught to students ". The teaching content determines the knowledge and skills of students to learn and also determines the students' ability and quality to be strengthened and improved in a certain aspect or certain aspects.

The content, knowledge and skills in the piano teaching of preschool education are relatively fixed, and their influence on the cultivation of aesthetic quality of music seems to be in a relatively stable state. In fact, there is difference in the emphases and difficulties of teaching content and difference in attention on each knowledge module, so students spend quite different time and energy in learning the different content. In contrast, the impact of teaching content on the cultivation of aesthetic quality of music is also in a relatively active state. From this point of view, for the cultivation of students' aesthetic quality of music, the aesthetic education of music in 
piano class of pre-school education must have a quite wide and profound content.

\section{BASIC WAYS to TRAIN STUdENTS’ AESTHETIC JUDGMENT IN THE PIANO TEACHING}

Different people have different aesthetic judgment, depending on their experience, intelligence, breeding and attitude towards life. The aesthetic judgment can be trained and improved through education. The ways to train students' aesthetic judgment in the piano teaching are as follows:

\section{A. Train Students' Aesthetic Feeling for the Piano Language}

The language in the piano is the expression form of it. With certain ability to perceive the aesthetic feeling in the piano language, teachers can use it to create the piano works full of passion and artistic appeal. Therefore, the training for students' aesthetic quality should start from their perception of the aesthetic feeling in the piano language. The piano has strong expressive force of language. The rules of the piano form the colorful changes of the piano language. Meanwhile, the performer can express the diversified emotions in playing the piano. Students can comprehend the beauty, understand the true essence of beauty and form the aesthetic quality through perceiving the piano language. The perception of the piano language is a necessary way for students to learn the piano. It is an important way for teachers to express and interpret the piano language for students to make them understand the piano language and train their aesthetic quality of the piano.

\section{B. Obtain the Source of Aesthetic Perception through the Association of Works}

The piano works resemble painting and calligraphy, simple on the surface but abundant in connotation. By contrast, it is more profound than the literary works, highly condensing the real life or things. In order to understand it, students must excavate and fully understand the works, build the art space of the piano works and then get the aesthetic feeling.

\section{Carry out the Aesthetic Cultivation through Masterworks}

Excellent works are full of artistic connotation and distinct era characteristics, referring to the treasure of culture and art preserved by the times. They are important materials for the aesthetic education in the piano teaching. On one hand, excellent works win universal praise, easier for piano accompaniment and for students to accept; on the other hand, these works are representative, get students' sense of identity and reduce the aesthetic obstacles of students. It can strengthen their aesthetic quality and accumulate the aesthetic experience. For example, excellent works like the Dance of Little Four Swans (selected from the dance drama of Swan Lake) present the aesthetic feeling in the piano accompaniment. At the meantime, it has extremely high value of dance appreciation, contributing richer aesthetic taste of students.

\section{Highlight Students' Personality and Exert the Aesthetic Appreciation}

Students are different in the understanding direction and degree of piano works because of personal tastes and backgrounds as well as strong points. The individual difference contributes to the phenomenon of "There are a thousand Hamlets in a thousand people's eyes" in appreciating the piano works. The aesthetic view with personal colors is students' feelings toward the works, manifesting their personality and ability and their in-depth understanding for the sense contained in the works. Although famous masters have different opinions on the artistic conception and emotion contained in the piano works, the benevolent see benevolence and the wise see wisdom. Therefore, teachers shall not define the meaning of works deliberately but give students the space of association and aesthetic appreciation on the basis of guidance. It meets the requirements of students' personalized development and guarantees the training of students' independent aesthetic consciousness and the creation of the piano works.

\section{CONCLUSION}

The training of students' aesthetic quality is the requirement of the modern educational development in the twenty-first century as well as the requirement for the improvement of students' integrated ability and the reform of quality-oriented education. The training of students' aesthetic quality in the piano education is an important teaching content of higher education of music. College music teachers should get refined internally and externally and train their comprehensive aesthetic ability, guiding students as well as building the strong backing of aesthetic quality, so as to let students become the appreciator of the piano music as well as excellent creators under the training of aesthetic quality.

\section{REFERENCES}

[1] Guan Songhe. Analysis on the Aesthetic Elements of Piano Music and Discussion on Its Application in the Piano Teaching in Normal Universities, master's thesis of Hebei Normal University, 2015(9)

[2] Xiao Ming. Discussion on the Embodiment of Aesthetic Characteristics of Art in the Piano Education, Journal of the Chinese Society of Education, 2013 (11)

[3] Gui Yuan. Research on the Piano Teaching to Children under the Aesthetic Education, master's thesis of Henan Normal University, 2015 (5). 